\title{
Gender and HIV-related discrimination in the health sector in Nigeria
}

\author{
Chinwe R. Nwanna \\ Department of Sociology, Faculty of Social Sciences, \\ University of Lagos, Akoka, Yaba, Lagos Nigeria \\ chironwa@yahoo.com
}

\section{Abstract}

This study explored the influence of gender on HIV-related discrimination in health care facilities in Lagos state from the perspectives of people living with HIV/AIDS. It hypothesized that women were more vulnerable to discrimination in the healthcare settings than men. Anchoring the analysis on Radical Feminism, the study argued that gender discrimination exacerbated HIV-related discrimination against female PLWHA in the health sector and that women's vulnerability to discrimination was based on the assumption that women were promiscuous. A purposive sample of 80 PLWHA was interviewed from September 2005 to April 2006. The results revealed that female PLWHA were more vulnerable to discrimination than the males. There were statistically significant differences between men and women's experiences in the following areas: mandatory HIV testing, unfair treatment, restricted movements, segregation and isolation from other patients. Rural female PLWHA; those aged 30 - 39 years, married, divorced, separated and widowed female PLWHA, those in paid employment and low income ones experienced discrimination more than the other categories of women. Gender mainstreaming, empowerment of women, formulation and enforcement of anti-discrimination laws, enforcement of CEDAW and education of health workers are recommended.

Key words: Discrimination, gender, health sector, HIV/AIDS, Lagos, PLWHA, socio-economic status.

\section{Résumé}

Cette étude a exploré l'influence de genre sur la discrimination $\mathrm{VIH}$-concernant dans l'équipement de santé publique dans l'état de Lagos des perspectives des gens vivant avec VIH/SIDA. II a émis une hypothèse que les femmes étaient plus vulnérables à la discrimination dans les cadres de soins médicaux que les hommes. En ancrant l'analyse sur le Féminisme Radical, l'étude a soutenu que la discrimination de genre a exacerbé la discrimination VIH-concernant contre PLWHA femelle dans le secteur de santé et que la vulnérabilité féministe à la discrimination a été fondée en supposant que les femmes soient immorales. Un échantillon délibéré de 80 PLWHA a été interviewé du septembre de 2005 à l'avril de 2006. Les résultats ont révélé que PLWHA femelles étaient plus vulnérables à la discrimination que les mâles. Il y avait des différences statistiquement significatives entre les hommes et les expériences féministes dans les régions suivantes : obligatoire VIH la mise à l'essai, le traitement injuste, a restreint des mouvements, 
une ségrégation et un isolement d'autres patients. PLWHA femelle rural; ceux âgés 30 - 39 ans, PLWHA femelle marié, divorcé, séparé et veuf, ceux-là dans l'emploi payé et les de revenu bas ont connu la discrimination plus que les autres catégories de femmes. Le genre mainstreaming, empowerment des femmes, la formulation et la mise en vigueur de lois d'antidiscrimination, la mise en vigueur de CEDAW et l'éducation d'ouvriers de santé est recommandé.

Mots clé : la Discrimination, le Genre, le secteur de Santé, VIH/SIDA, Lagos, PLWHA, statut socio-économique.

\section{Introduction and background of the study}

HIV/AIDS has become one of the greatest challenges that threaten the existence and survival of the developing world particularly Sub-Saharan Africa. It has been ravaging the human population worldwide. Globally, about 33 million people were living with the disease in 2007 (UNAIDS, 2008). Nigeria has the second highest cases of HIV infection in Sub-Saharan Africa. Since the first AIDS case was diagnosed in 1986, the prevalence rate has increased exponentially from $1.8 \%$ in 1992 to $4.5 \%$ in 1996 and 5.8\% in 200 I (Nigerian Institute of Medical Research (NIMR), 2000; National AIDS \& STD Control Programme, (NASCP), 2002). The figure dropped to $5 \%$ in 2003 and further down to $4.4 \%$ in 2005 (Federal Ministry of Health [FMOH], 2006). It is still declining. By the end of 2007, an estimated $3.1 \%$ of adults aged $15-49$ years were living with HIV/AIDS in Nigeria (UNAIDS, 2008). Initially, more men were afflicted than women [62\% against 38\%], (Nwanna, 2003). Presently, there is a feminization of the infection. In 2007, women aged 15 years and above represented $53.8 \%$ of all cases of HIV/AIDS (UNAIDS, 2008). AIDS has claimed so many lives in Nigeria. Approximately 170,000 people died from AIDS in 2007 alone
(UNAIDS, 2008). This has affected the average life expectancy, which has declined from 53.8 years for women and 52.6 years for men in 1991 to 46 for women and 47 for men in 2007 respectively (WHO, 2008). In addition to these health consequences, the disease has accentuated social discrimination. The explication of the fatal nature of the disease, especially where there is no known curative measure and its association with homosexuality and promiscuous sexual relations have occasioned the rejection of people living with HIV/AIDS. Also, ignorance of the disease and the phobia it provokes in people have resulted in self-defence mechanisms among the public, including health workers, through segregation, exclusion, or denial of equal opportunities (Mann 1987; Herek and Glunt 1988).

Discrimination may occur in different forms in different contexts. It has become a powerful tool of social control and an intractable problem associated with the AIDS epidemic throughout the world. The extent to which one suffers such treatment is determined by his/her social and economic status which is often determined by the prospects available to him/her. Discrimination has been shown to delay HIV testing, restrict utilization of preventive programmes, and hinder the 
adoption of preventive behaviours like condom use and HIV status disclosure (FMOH, 2003; Brooks et al., 2005).

Discrimination usually builds upon and reinforces pre-existing fears and prejudices about poverty, gender, sex and sexuality. In many places, people living with HIV/AIDS (PLWHA) are perceived as having had sex with sex workers or prostitutes (if they are men), or as having been 'promiscuous' (if they are women). Furthermore, in many parts of the world, HIV is seen as a 'woman's disease', like many other forms of sexually transmitted infections. HIV/AIDS-related discrimination therefore plays into, and reinforces, existing social stereotypes and inequalities; such inequalities that make women seem inferior to men. Arachu and Farmer (2005) argue that discrimination is linked to power and domination in the community as a whole, playing a key role in producing and reproducing relations of power and control. They contend that every society is shaped by large-scale social inequalities that are rooted in historical and economic processes that determine the distribution and outcome of HIV/AIDS. They opine that social inequalities determine, in large part, who suffers from HIVrelated discrimination. Understanding HIV-related discrimination therefore, requires an understanding of how social inequalities foster discrimination. In view of the afore-stated, socio-economic status of the PLWHA is an important issue to study because of its power and influence in society. For example, it is argued that in patriarchal societies gender inequality determines the extent to which sexism marks the course of HIV infection (Arachu and
Farmer, 2005). In such societies, like Nigeria, a disclosure of HIV infection may provoke discrimination and domestic violence against female PLWHA than in environments where women enjoy gender equity.

In Nigeria, there are reports of discriminatory practices against PLWHA such as mandatory HIV testing particularly for pregnant women (lwuagwu et al., 2003), termination of jobs (Iwuagwu et al., 200 I and 2003; Akparanta - Emenogu, 2002; Adirieje, 2003; Durojaiye, 2003). PLWHA have been excluded from social activities, rejected and abandoned by their families (Iwuagwu et al., 2003). Outright denial of any care in public as well as private health facilities has also been reported (Adebajo et al., 2003; Reis et al., 2005).

Previous studies have shown that social discrimination by health workers is pervasive in the health sector (Adebajo et al, 2003; Iwuagwu et al., 200 I and 2003; Reis et al. 2005) but experiences of PLWHA have not been empirically examined. Similarly, gender and discrimination within health facilities have yet to be empirically assessed. In a number of societies, women and men are not dealt with in the same way when they are infected by HIV/AIDS. Men are more likely than women to be accepted by family and community. This study therefore hypothesized that women were more vulnerable to discrimination in the healthcare facilities than men. It therefore, explored the influence of gender on discrimination experienced by PLWHA in the health sector and subsequently assessed the socio-economic characteristics of those vulnerable to discrimination. The data were generated from a study con- 
ducted from September 2005 to April 2006 among non-infected and infected people.

\section{Literature review and theoretical underpinnings}

Definition of key terms

Gender: This connotes cultural, social and psychological differences between males and females while sex refers to physical differences of the body. In this study, gender denotes (I) male or (2) female.

HIV-related discrimination: Gilmore and Somerville (1994) define discrimination as any form of distinction, exclusion or restriction affecting a person by virtue of his/her characteristic. UNAIDS developed a protocol for the identification of discrimination against people with HIV/AIDS. According to the protocol, HIV/AIDS-related discrimination is defined as any measure entailing any arbitrary distinction among persons depending on their confirmed or suspected HIV sero-status or state of health (UNAIDS, 1996). Aggleton and Parker (2002) assert that discrimination occurs when a distinction is made against a person that results in his or her being treated unfairly and unjustly on the basis of belonging, or being perceived to belong to a particular group. In this study, therefore, discrimination was presented as negative attitudes, beliefs, attributes, behaviours, activities and experiences that occurred in social interactions.

Socio-economic status: Socio-economic status (SES) is often conceptualized as a fundamental factor of inequalities. It refers to a composite ranking which can be used to describe a person's overall social position. It refers to prestige, honour, respect and lifestyle associated with different positions or groups in society (Gerth and Mills, 1958). SES is not only correlated with wealth and income but can also be derived from achieved characteristics such as educational attainment and occupational prestige, and from ascribed characteristics such as race, ethnicity, gender and family pedigree. Hence, it is a multidimensional concept. For this study therefore, SES was a characteristic of economic, social and physical environments in which individuals lived and worked, as well as a demographic characteristic.

Review of earlier studies

HIV-related discrimination has been studied extensively globally but locally there are limited empirical studies on gender and discrimination. Researches and inquiries into discrimination against PLWHA had shown that it could affect almost every aspect of a person's life. Surveys of people's attitudes and opinions about such things as working with someone with HIV/AIDS, housing for PLWHA, or isolation of PLWHA had found that a substantial proportion held highly discriminatory views. (Herek and Capitano, 1999; FMOH, 2003; NPC and ORC/Macro, 2004; Ekong, 2005; and Adeokun et al., 2006). Such attitudes persist despite education about the fact that there is no risk of HIV infection in many common settings and activities.

Several studies have found that the attitudes of health care workers to HIVpositive people were discriminatory; because they feared in part becoming infected with HIV (Gerbert et al., 1991; Weinberger et al., 1992). There were more insidious reasons for people in 
government, leaders in positions of influence and members of the community, who had less intimate contact with HIV positive people to treat them with negative attitudes. Studies have also indicated that social discrimination in the health sector was rife. Many people after their diagnosis found that treatment was suddenly denied them or delayed. Breaches of confidentiality by health-care workers were also very common (The Asia-Pacific Network of People Living with HIV/AIDS (APN+), (2004). According to the APN+ study, denial or delay of treatment and breaches of confidentiality by healthcare workers were prevalent. People who were unprepared to take HIV tests were likely to experience subsequent discrimination from a health-care worker (20\% against $14 \%$ ), or denied medical treatment $(16 \%)$ compared to $10 \%$ who perceived themselves prepared for their test. People coerced into HIV testing (22\%) were likely to pay more than others $(8 \%)$ for the same services because of their status and more likely than other respondents to participate in clinical studies $(32 \%$ vs 17\%). APN+ study was supported by the report of Fredriksson and Kanabus (2004). According to their report, lack of confidentiality was repeatedly mentioned as a particular problem in health care settings. Many PLWHA did not get to choose how, when and to whom to disclose their HIV status. When surveyed recently, $29 \%$ of PLWHA in India, $38 \%$ in Indonesia, and over $40 \%$ in Thailand said their HIV+ status was revealed to someone else without their consent. There were significant differences in medical practice in various countries and even health care facilities within a single country. In some hospitals, signs were placed near people living with HIV/AIDS with words such as 'HIV-positive' and 'AIDS' written on them. However, some studies reported positive attitudes of the health workers. Sherafat-Kazemzadeh et al., (2004) revealed that nearly half of the PLWHA respondents in their study believed that medical staff had a fairly good to very good attitude, although one-fifth of the respondents were convinced that the attitudes of medical staff were bad.

In his own contribution in Sub-Saharan Africa, Young (2004) reported that Quality Assurance Project (QAP) in Rwanda evaluated HIV/AIDS knowledge, attitudes, and practices of health providers in Prevention of Mother to Child Transmission (PMTCT) services. Results revealed that HIV+ women who had gone through PMTCT programmes reported violations of confidentiality, disrespect and inadequate attention against them at health centres when in labour. Discussions further revealed that the disrespect they received at the healthcare facilities during labour and delivery was a hindrance to HIV + women in need of care.

In Nigeria, Adebajo et al., (2003) reported a study conducted in Lagos to assess amongst others, the attitudes of 300 health workers towards PLWHA using a structured self-administered questionnaire. The findings showed strong indications of discrimination. About $80 \%$ of the health workers thought the PLWHA were dangerous to others and $35 \%$ were of the view that they should be quarantined. Almost $58 \%$ of the respondents did not want the PLWHA to be admitted to the wards. The findings further revealed 
that a large percentage (82\%) would not visit the PLWHA at home. These findings are stunning because health workers are supposed to be better informed about HIV/AIDS than the general public. They also have a responsibility to provide quality care and services for PLWHA without stigmatization or discrimination. Reis et al., (2005) investigated I,02I health-care professionals (doctors, nurses, and midwives) working directly with patients with HIV/AIDS in I I I health-care facilities in 4 states of Nigeria. The results indicated that $9 \%$ of the workers refused to care for HIV/AIDS patients; another $9 \%$ refused to admit patients with HIV/AIDS into hospitals and $59 \%$ agreed that PLWHA should be in separate wards. About $40 \%$ believed health-care professionals living with HIV/AIDS should not be allowed to work in any other area of health-care where they had direct contact with other patients. About $8 \%$ felt that treating someone with HIV/AIDS was a waste of resources. One factor that could be fuelling discrimination among doctors and nurses was the fear of exposure to HIV and probably because they lacked protective equipment. Another factor might be frustration for not having medicines to treat HIV/AIDS patients, who were seen as 'doomed' to die.

Evidence has shown that women experience discrimination more than the men. The APN+ (2004) study further found that the levels of discrimination experienced by men and women were significantly different, with women bearing the brunt of AIDSrelated discrimination. Mandatory testing of pregnant women was increasingly popular throughout Asia and with it came a vast range of human rights violations, including increased violence against women. Validating these findings, qualitative studies reported by Iwuagwu et al., (200I, 2003) revealed that a pregnant PLWHA was tested for HIV without her informed consent. The woman recounted how she registered for antenatal care in a private hospital near her house and was asked to do an HIV test which she refused. She was rejected in that hospital. She then went to a government health centre where she was sent to do a blood test. She alleged that the form did not indicate an HIV test, hence she did the test. On her next appointment, she was referred to a teaching hospital without any explanation or counselling. On her way, out of curiosity, she read the laboratory result and found that she was HIV+ and became devastated. At the teaching hospital, her letter was passed from one nurse to another and she was eventually not attended to. In another report by Iwuagwu et al., (200 I; 2003) a woman was denied access to health care when she delivered a baby. The female PLWHA narrated how the hospital staff refused to attend to her because of her HIV+ status. She said that everybody in the hospital knew she was HIV+ and they heavily "masked, gloved and gowned" themselves as "if HIV was an air-borne disease". After delivery she was not cleaned up nor was her episiotomy sutured predisposing her to many childbirth-related complications. A male PLWHA in the Centre for Right to Health (CRH) study recounted how his case note was labelled "HIV positive" and how his treatment was delayed when he went 
to extract a tooth in a general hospital (Iwuagwu et al., 200I; 2003). The hospital workers tossed his case note from one person to the other. They were heavily clothed when they eventually extracted the tooth, after postponing the surgery twice.

Numerous perspectives have been advanced on social discrimination against people living with HIV/AIDS. However, to explain gender and discrimination a combination of two theories was adopted and examined below. They are power theory by Foucault (1978) and radical feminism by Rich (1980). These two theories tried to explicate why women were more vulnerable to discrimination than men. Foucault (Ritzer, 1996) uses the concept of power to explicate discrimination and defines it as a multiplicity of force relations that comes from everywhere and exists in a variety of micro settings. To him, power is linked to knowledge. He observed that through knowledge of sexuality, societies came to exercise more power over sex. He avers that sexuality is a dense transfer point for relations of power and masculinity a powerful 'limit' that restricts the subjective experience of male identifying individuals (Foucault, 1978). He goes on to postulate that construction of homosexuality as the very negation of masculinity and equating it with an equally marginalized femininity such that gay men are often stereotyped as effeminate, passive, unstable and ultimately unmanly (Altman, 1972) leads to homophobia. When AIDS was discovered among the homosexuals in the US in 1981, it was followed by another epidemic, social discrimination.

The other perspective, radical femi- nism, argues that women are violently oppressed by the system of patriarchy as practised by men and male-dominated organizations (Rich, 1980). Violence can be overt or subtle and exists whenever one group controls, in its own interests, the life chances, environments, actions and perceptions of another group, as men do women within the home: spouse abuse or as non-infected people do PLWHA particularly women: persecution of female PLWHA. Evidence has shown that women experience harsher forms of discrimination. They are perceived as the "carriers" or "vectors" of HIV/AIDS because they are often the first to be diagnosed HIV+ either through antenatal screening or the birth of a sick child. They are held culpable for having brought AIDS into the family. As such they are often subject to emotional harassment, eviction from their homes or are physically abused for their HIV+ status.

The above review of literature shows that most of the studies focused on perpetrators rather than the targets i.e. the PLWHA and that healthcare providers were often discriminatory. Studies focusing on PLWHA in Nigeria only adopted focus group discussions or in-depth interviews that provided only qualitative data. However, these have limitations since qualitative analysis cannot give precise statistical measurements on the extent and gravity of social discrimination against persons living with HIV/AIDS. Hence, quantitative data were required. Empirical research on the experiences of PLWHA is very

I. Source: http://www.aidslaw.ca/ maincontent/issues/ discrimination 
important. Reis et al., (2005), after studying the attitudes and behaviour of health workers towards the PLWHA, recommended that the feelings and experiences of PLWHA should be studied. To fill this gap in knowledge, focus group discussions (FGDs) and face-toface interviews were used to collect both qualitative and quantitative data from the PLWHA.

The review of the theories confirmed that PLWHA started experiencing discrimination because of the origin of AIDS which was associated with homosexuality and others classified as high risk groups. Female PLWHA, in particular, experience more discrimination than men because of power relations between men and women and/or because of social inequalities in the society at large. Health workers would want to control life chances such as denial or delay of treatment. They may refuse to admit PLWHA patients into the hospital or even disrespect them.

\section{Methods of the study}

Research design

The study was a cross sectional study which adopted a combination of correlational and comparative research designs. These two research designs were found useful since the study involved the assessment of relationship between socio-economic variables of PLWHA and discrimination against them. Correlational design was used to demonstrate co-variation between the dependent and independent variables through the application of bivariate and Chi square analyses. The dependent variables were the different dimensions of discrimination e.g. mandatory HIV testing, unfair treatment, isolation and segregation from other patients. The independent variables were the socioeconomic characteristics of PLWHA such as gender, age, marital status, education, employment and income. The comparative method was applied to compare data between and within the male and female PLWHA.

\section{Study settings}

The study was conducted in two local government areas (LGAs) of Lagos State namely Epe and Lagos Mainland. Epe LGA, a riverine area, had a population of 101,464 with 95 localities by the time of the 199I census (National Population Commission (NPC), 1997) which has increased to I8I, 409 by the 2006 census (Federal Government Printer [FGP], 2007). The 199I census data were used because at the time of the study, the 2006 census data were not yet available. Epe LGA includes a number of isolated villages or settlements predominantly occupied by the ljebus, a Yoruba sub-ethnic group. The people are predominantly farmers, polygynyous, and Muslims. The LGA was chosen because of her high HIV prevalence rate $(6.9 \%)$ in 1999 (NIMR, 2000) although 2003 estimate was $4.2 \%(\mathrm{FMOH}, 2004))$. Factors identified as driving the HIV infection include poverty, promiscuity, low economic status of women, early marriages that lead to early separation, polygyny, changing spouses, skin scarification (FHI, 200I) and fishing. The LGA has 17 health facilities (Community Participation for Action in the Social Sectors (COMPASS), 2005).

Lagos Mainland LGA, on the other hand, had 17 localities with a population of 273,079 by the 1991 census (NPC, 1997). The population was 317,720 as 
at March 2006, (FGP, 2007). Lagos Mainland LGA was selected because of her urbanized status and the presence of Nigeria Institute of Medical Research (NIMR), Yaba, Lagos, one of the popular centres for the National Antiretroviral Therapy Programme in Nigeria. The Institute facilitated the identification of the PLWHA. The LGA stands out because of many features such as the Nigerian Railway headquarters at Iddo, tertiary institutions, military bases and referral hospitals, motor parks for luxurious buses that harbour long-distance drivers, travellers, students, urchins, area boys, alaye boys, drug users, female sex workers and youths. Other predisposing activities to the risk of HIV/AIDS include ear, nose and eyelid piercing, nail cutting and circumcision with unsterilized instruments. Situated in the LGA, are 10 health facilities (COMPASS, 2005). Her HIV prevalence rate was not stated but was estimated to fall within the range in Lagos metropolis i.e. between $1.7 \%$ in Lagos Island LGA and $7.7 \%$ in Ikeja LGA, the state capital (FMOH, 2004).

Sample and sampling techniques

For the sample size, adequate data on the total number of PLWHA in Lagos state were not available. This informed the purposeful determination of the sample size (100). To facilitate the identification of the PLWHA, the researcher applied to Nigeria Institute of Medical Research (NIMR), Yaba, Lagos, for assistance. NIMR, as one of the first centres for the National Antiretroviral Therapy Programme in Nigeria and therefore has many PLWHA who visit it to collect drugs. The request was granted after the assessment of the research proposal and instruments by the Institutional Review Board (IRB) of NIMR. With the approval letter and the assistance of the NIMR staff, Network of PLWHA, NGOs and other support groups, we were able to reach the PLWHA.

A purposive sampling technique was used to select 80 PLWHA: 50 from Lagos Mainland LGA and 30 from Epe LGA (Table I below). Thirty PLWHA respondents from Epe LGA were investigated instead of fifty. Twenty of them were identified in Epe General Hospital (nineteen women and one man). The remaining ten (four men and six women) who lived in Epe LGA at the time of the study were identified at NIMR, Yaba, when they came for treatment. The Medical Director of Epe General Hospital reported that when people tested positive to HIV and were referred to NIMR for confirmatory tests or advised to get back to join others in the support group, they absconded from the hospital. They lost track of them. A method of snowball was also utilised to identify PLWHA. An NGO, Health Matters Incorporation, based in Ebute Metta, assisted in identifying one PLWHA who was resident in Lagos Mainland LGA and who identified about two PLWHA who in turn invited others and so on. Eight of the Lagos Mainland LGA respondents were so identified and interviewed in researcher's office. Among the 80 PLWHA surveyed, 30 (37.5\%) were men while $50(62.5 \%)$ were women (Table I below). The data showed that more women than men acceded to the interviews. It was the intent of this study to investigate equal number of males and females but as a result of the problems stated above, 5 (I6.7\%) 
males and 25 (83.3\%) females who lived in Epe LGA were investigated while 25 of each sex were studied in Lagos Mainland LGA (Table I).

Table I: Distribution of total number of PLWHA by gender and place of residence

\begin{tabular}{lcccccc}
\hline & \multicolumn{2}{c}{ Epe } & \multicolumn{2}{c}{ Lagos Mainland } & \multicolumn{2}{c}{ Total } \\
\hline Gender & N & $\%$ & N & $\%$ & N & $\%$ \\
\hline Male & 5 & 16.7 & 25 & 50.0 & 30 & 37.5 \\
Female & 25 & 83.3 & 25 & 50.0 & 50 & 62.5 \\
Total & 30 & 100.0 & 50 & 100.0 & 80 & 100.0 \\
\hline
\end{tabular}

Ethical considerations

In addition to the assessment of the protocol by IRB, research ethics were fully observed. Oral consent was obtained. There was no coercion of any kind.

Research instruments for data collection

In addition to desk review of secondary data, validated semi-structured interview schedule and a focus group discussion (FGD) guide were developed by the researcher. The interview schedule had 92-items and consisted of seven sections. Section I had Socio-economic characteristics and Section 2 dealt with information about HIV status. Section 3 was on the Conception and ethnic perception of HIV/AIDS while Sections 4 7 interrogated discrimination in different settings: the health sector, workplace, educational sector and within the family and community. The FGD guide contained key questions corresponding to those in the interview schedules. Only the items that concerned questions in the health sector were explained briefly here.
Questions on HIV-related discrimination in the health sector

The PLWHA were asked whether they had ever been refused or denied treatment because of their HIV status in a public or private hospital / clinic; whether they had experienced mandatory HIV tests; or HIV tests without their knowledge and consent; whether they were treated like any other patient; treated with contempt; movement restricted to certain areas in the hospitals; avoided by health workers; isolated from other patients; health workers used special equipment/instruments to treat them; received treatment regularly while on admission; ever been charged higher than other patients at a health facility because of HIV/AIDS status. In all the questions, response options were "Yes and No". In some questions "Yes" was conceived as discrimination while in some such as "Whether they were treated like any other patient and whether they received treatment regularly while on admission", it represented non-discrimination.

Data collection and analysis

Data were collected between September 2005 and April 2006 with the help 
of eleven research assistants (RAs) who were trained in the art of interviewing. Due to the heterogeneous nature of Lagos, efforts were made to match linguistic and cultural diversity of the state with those of the RAs. Ability to speak and understand one of the three major Nigerian languages was a criterion for participating in the study. There were four teams consisting of a Yoruba and an Igbo in Lagos Mainland LGA. One team in Lagos Mainland had three RAs (two Yorubas and one lgbo). Pidgin English was allowed in a situation where a respondent could not speak any of the languages. In Epe, a team of two Yoruba RAs conducted the interviews because Epe was predominantly inhabited by the Yorubas. The researcher supervised the teams and also conducted some interviews. Of the four proposed sessions of FGDs, three were achieved (two in Lagos Mainland LGA and one in Epe LGA). This was attributed to the absence of male PLWHA in Epe LGA. Each FGD was homogeneous in terms of sex except in Epe where only one male PLWHA was identified. $\mathrm{He}$ joined the female PLWHA during the FGD and was later interviewed separately. The main objective of ensuring homogeneity along gender lines was to prevent inhibitions that could affect the quality of discussions or lead to domination of one gender which could compromise a clear picture of the different views of men and women about social discrimination. Six people participated in each FGD session. Coordination of each session was assisted by two RAs who served as note takers. The discussions were also tape recorded with the knowledge and full consent of the par- ticipants. In both LGAs, the FGDs were conducted in English language. The discussions were later transcribed.

Data were analyzed using the Statistical Package for Social Sciences (SPSS) versions II and I3. Analyses were run for qualitative, quantitative and comparative data.

\section{Fieldwork challenges}

Identifying PLWHA in Epe was problematic. There was no non-governmental organization (NGO) based in Epe that could facilitate the identification of the PLWHA. Apart from those identified by the Epe General Hospital, no one was willing to identify with the virus in the community or give any useful information about any PLWHA. Only 30 PLWHA respondents were studied as opposed to 50 .

\section{Results of the study}

\section{Socio-economic characteristics of respondents}

Of the 78 people living with HIV/AIDS (PLWHA) who obliged to provide their ages, more than two-fifths were found in the age group 30-39 years and the mean age was 36.26 years (Table 2 below). Among the females, $47.9 \%$ of the respondents were in the age category $30-39$ years. About $36.78 \%$ of the male respondents were similarly classified. One half of the men were above 40 years old. The mean ages were 34.2 years for the females and 39.5 years for men. These mean ages show that women were younger than the men. There was a statistically significant difference between the two sexes on the basis of age. People aged 15-29 years have been shown to have the highest HIV prevalence rate in previous studies 
(NIMR, 2000; FMOH, 2006). On the contrary, this study found that this age group was the least investigated. This could be attributed to the minimum age (I8 years) set for the respondents in this study which excluded those aged 15 to 17 years. It could also be that those aged 18-20 years declined to participate in the study; or worse still, did not visit the treatment centres during the study period. It could also be that enlightenment campaigns against HIV/ AIDS of the past years are yielding fruits. May be the youths are abstaining from sexual intercourse or effectively using condoms. This could explain the predominance of older respondents. This finding reflects that HIV/AIDS infects the most active and productive age groups and confirms the findings of the 1999 and 200I Sentinel Surveys (NIMR, 2000; NASCP, 2002).

Table 2: Socio-economic characteristics of the respondents by sex

\begin{tabular}{|c|c|c|c|c|c|c|}
\hline \multirow{2}{*}{$\begin{array}{l}\text { Socio-economic characteristics } \\
\qquad \text { Age }\end{array}$} & \multicolumn{2}{|c|}{ Male } & \multicolumn{2}{|c|}{ Female } & \multicolumn{2}{|c|}{ Total } \\
\hline & $\mathrm{N}$ & $\%$ & $\mathrm{~N}$ & $\%$ & $\mathrm{~N}$ & $\%$ \\
\hline $18-19$ & 4 & 13.3 & 14 & 29.2 & 18 & 23.1 \\
\hline $30-39$ & 11 & 36.7 & 23 & 47.9 & 34 & 43.6 \\
\hline $40+$ & 15 & 50.0 & 11 & 22.9 & 26 & 33.3 \\
\hline No response & - & - & 2 & - & 2 & - \\
\hline Total & 30 & 100.0 & 50 & 100.0 & 80 & 100.0 \\
\hline \multicolumn{7}{|l|}{$X^{2}=6.604, p<0.05$} \\
\hline Mean age & $39.5 y r s$ & & $34.2 y r s$ & & $\begin{array}{c}36.26 y r \\
s\end{array}$ & \\
\hline \multicolumn{7}{|l|}{ Marital Status } \\
\hline Single & 10 & 33.3 & 16 & 32.0 & 26 & 32.5 \\
\hline Married & 17 & 56.7 & 15 & 30.0 & 32 & 40.0 \\
\hline Divorced/separated/widowed & 3 & 10.0 & 19 & 38.0 & 22 & 27.5 \\
\hline Total & 30 & 100.0 & 50 & 100.0 & 80 & 100.0 \\
\hline \multicolumn{7}{|l|}{$X^{2}=8.689, p<0.05$} \\
\hline \multicolumn{7}{|l|}{ Level of education } \\
\hline No education/primary & 6 & 20.0 & 10 & 20.0 & 16 & 20.0 \\
\hline Secondary education & 13 & 43.3 & 22 & 44.0 & 35 & 43.8 \\
\hline Tertiary & $\mathrm{II}$ & 36.7 & 18 & 36.0 & 29 & 36.3 \\
\hline Total & 30 & 100.0 & 50 & 100.0 & 80 & 100.0 \\
\hline \multicolumn{7}{|l|}{$X^{2}=0.004, p>0.05$} \\
\hline \multicolumn{7}{|l|}{ Employment status } \\
\hline Unemployed & 10 & 33.3 & 24 & 48.0 & 34 & 42.5 \\
\hline Self-employed & 14 & 46.7 & 19 & 38.0 & 33 & 41.3 \\
\hline Paid employment & 6 & 20.0 & 7 & 14.0 & 13 & 16.3 \\
\hline
\end{tabular}




\begin{tabular}{lcccccc}
$\begin{array}{l}\text { Total } \\
X^{2}=1.706, p>0.05\end{array}$ & 30 & 100.0 & 50 & 100.0 & 80 & 100.0 \\
$\quad \begin{array}{l}\text { Income } \\
\text { No income }\end{array}$ & 10 & 40.0 & 24 & 54.5 & 34 & 49.3 \\
Less than N10,000 & 7 & 28.0 & 12 & 27.3 & 19 & 27.5 \\
NI0,00I - N20,000 & 3 & 12.0 & 4 & 9.1 & 7 & 10.1 \\
N20,00I+ & 5 & 20.0 & 4 & 9.1 & 9 & 13.0 \\
No response & 5 & & 6 & & 11 & \\
Total & 30 & 100.0 & 50 & 100.0 & 80 & 100.0 \\
$X^{2}=2.275, p>0.05$ & & & & & & \\
\hline
\end{tabular}

The table shows that one-third (32.5\%) of the respondents were never married at the time of the study. About $33.3 \%$ of the males and $32.0 \%$ of the female respondents constitute this percentage. About $56.7 \%$ of the male respondents and $30.0 \%$ of females were married amounting to two-fifths of the total sample. A significant proportion (27.5\%) of the PLWHA was divorced, separated and widowed. There was a higher percentage of the divorced, separated and widowed PLWHA among women $(38.0 \%)$ than men (10.0\%). This could be attributed to their HIV status which had predisposed them to divorce; separation or widowhood (if their spouses were also afflicted and had died of AIDS). The difference between men and women was statistically significant.

Around $43.8 \%$ of the PLWHA had secondary education, post secondary education $(36.3 \%)$ while $20 \%$ had no formal education or had stopped at primary level. This indicates that majority of the respondents are well educated. Similar patterns were found among the men and women. There was no significant difference between the men and the women. The findings confirm that
HIV/AIDS affects both educated and uneducated persons.

On employment status, Table 2 also shows that 34 of the total respondents, representing $42.4 \%$, were unemployed. About $48.0 \%$ of the women and $33.3 \%$ of the men make up this group. About $57.6 \%$ of the respondents were employed. A greater proportion $(41.3 \%)$ of the employed was selfemployed while those in the paid employment were less (16.3\%). Disaggregating by sex shows that $46.7 \%$ of men were self-employed while $38.0 \%$ of women were so classified. The remaining one-fifth of the men and more than one-tenth of the women were in paid employment. The percentage of unemployed PLWHA was higher among women than men while a greater proportion of men were selfemployed either because of the level of unemployment in the general population $(37.9 \%)$ or as a result of termination of employment on grounds of being HIV + . It was revealed in the main study that $47.4 \%$ of the PLWHA whose status was disclosed to their organizations had stopped work $(80.0 \%$ stopped work voluntarily because of self-imposed discrimination, discrimina- 
tion by colleagues and ill health while $20.0 \%$ were dismissed because of their HIV status). PLWHA need employment to earn income in order to cope with the financial exigencies of their condition. A higher proportion of gainfully employed respondents were men. However, the difference between the two sexes on the basis of employment status was not statistically significant.

Since over two-fifths of the PLWHA respondents were not working, a corresponding proportion also did not receive income as indicated in the table above. Hence most of them would not be economically empowered to cope with the vicissitudes of HIV infection. HIV/AIDS tends to impoverish those living with it due to its protracted nature and its high management cost. A significant proportion $(27.5 \%)$ earned less than NIO, 000.00 a month. The average income of the PLWHA was N9,198.55. This was just above the national minimum wage of $\mathrm{N7,500}$. Only $10.1 \%$ received between $\mathrm{NI}, 00 \mathrm{I}$ and N20,000 per month and II.3\% received $\mathrm{A} 20,00 \mathrm{I}$ and above monthly. Most of the respondents therefore belonged to the lower income group. About eleven of the employed did not divulge their incomes. Disaggregating the respondents into sexes shows that $54.5 \%$ of female respondents compared to $40.0 \%$ of the males earned no income. This could be attributed to loss of livelihood on the grounds of HIV status. It could also be due to low socio-economic status of women. There was no statistically significant difference between the men and women on the basis of income. This study shows that HIV/ AIDS increases poverty situation of the individuals and in the country in general. Poverty increases vulnerability to HIV infection.

\section{Forms of HIV-related discrimination experienced by PLWHA in the health facilities}

Table 3 below highlights the diverse forms of discrimination experienced by men and women living with HIV/AIDS in the health facilities. A significant proportion $(21.5 \%)$ of the total respondents was subjected to mandatory HIV testing by health workers at one time or the other. This finding validates previous study by Iwuagwu et al., (2003). About $32.0 \%$ of women and only about $3.4 \%$ of men suffered this form of discrimination. This difference was statistically significant. One-quarter of the PLWHA were not treated just like any other patient. Among these were $36.7 \%$ of the female respondents compared to $6.7 \%$ of the male PLWHA. The difference between men and women in this respect was statistically significant. Out of the 80 PLWHA, $22.8 \%$ expressed dissatisfaction with health workers' attitudes and behaviours towards them. They reported that health workers restricted their movement to certain areas within the hospital premises. The ratio of men to women who had this experience was 1:3 and this was statistically significant. Furthermore, $17.7 \%$ of the total respondents were avoided by health workers. Approximately $24.5 \%$ of the female respondents compared to $6.7 \%$ of male respondents had been shunned by health workers (Table 3 below). There was a statistically significant difference between men and women.

A male FGD participant narrated how he reported sick in his company's 
clinic and was referred to another hospital which requested for various clinical tests including HIV test. He revealed that a nurse who used to be friendly with him tried to avoid him when she learnt that he was HIV positive. He succinctly narrated his ordeal:

As for me, I fainted when I was diagnosed HIV positive in $200 \mathrm{I}$. I wasn't even sick. I just had itches and was referred to the clinic by my company's doctor. It reoccurred after treatment and the doctor told me to go for tests including HIV/AIDS test. I went for the tests and I saw negativenegative until I got to the bottom of the paper where they wrote positive for HIV. I just fainted. I didn't know how I got myself back. When I went back to the clinic to get my drugs, the nurse that used to be friendly with me recoiled from me on seeing the test result.

Besides reporting the negative attitude of the nurse, his evidence also revealed the shock people usually experienced when they received the results of HIV tests without counselling. Gerbert et al. (I99I) and Weinberger et al. (1992) found that fears of contagion and of death have clear negative effects on health care providers' attitudes towards HIV-positive patients and subsequently their treatment. Health care providers also fear discrimination themselves because of their work with HIVpositive patients (Durham, 1994). Apart from avoidance, health workers also physically isolated $19.0 \%$ of PLWHA respondents from other patients. This proportion represents $26.5 \%$ and $6.7 \%$ of women and men respectively. The difference between the two LGAs was statistically significant.

Table 3: Forms of HIV-related discrimination by gender

\begin{tabular}{lc|c|c|c|c|c}
\hline HIV-related discrimination & \multicolumn{2}{c}{ Male } & \multicolumn{3}{c}{ Female } & \multicolumn{2}{c}{ Total } \\
& $\mathrm{N}$ & $\%$ & $\mathrm{~N}$ & $\%$ & $\mathrm{~N}$ & $\%$ \\
\hline Ever been mandated to have HIV tests & & & & & & \\
Yes & $\mathrm{I}$ & 3.4 & 16 & 32.0 & 17 & 21.5 \\
No & 28 & 96.6 & 34 & 68.0 & 62 & 78.5 \\
Total & 29 & 100.0 & 50 & 100.0 & 79 & 100.0 \\
$X^{2}=8.860, \mathrm{p}<0.05$ & & & & & & \\
Treated like any other patients & & & & & & \\
\hline Yes & 28 & 93.3 & 31 & 63.3 & 59 & 74.7 \\
No & 2 & 6.7 & 18 & 36.7 & 20 & 25.3 \\
Total & 30 & 100.0 & 49 & 100.0 & 79 & 100.0 \\
$X^{2}=8.898, p<0.05$ & & & & & & \\
Movement ever been restricted? & & & & & & \\
Yes & 3 & 10.0 & 15 & 30.6 & 18 & 22.8 \\
No & 27 & 90.0 & 34 & 69.4 & 61 & 77.2 \\
Total & 30 & 100.0 & 49 & 100.0 & 79 & 100.0
\end{tabular}


$\mathrm{X}^{2}=4.494, \mathrm{p}<0.05$

Avoided by health workers?

\begin{tabular}{lcccccc} 
Yes & 2 & 6.7 & 12 & 24.5 & 14 & 17.7 \\
No & 28 & 93.3 & 37 & 75.5 & 65 & 82.3 \\
Total & 30 & 100.0 & 49 & 100.0 & 79 & 100.0 \\
$X^{2}=4.054, \mathrm{p}<0.05$ & & & & & & \\
Isolated from other patients? & & & & & & \\
Yes & 2 & 6.7 & 13 & 26.5 & 15 & 19.0 \\
No & 28 & 93.3 & 36 & 73.5 & 64 & 81.0 \\
$X^{2}=4.773, p<0.05$ & 30 & 100.0 & 49 & 100.0 & 79 & 100.0 \\
Denied admission into public health & & & & & & \\
facility? & & & & & & \\
Yes & 2 & 6.9 & 5 & 10.4 & 7 & 9.1 \\
No & 27 & 93.1 & 43 & 89.6 & 70 & 90.9 \\
Total & 29 & 100.0 & 48 & 100.0 & 77 & 100.0 \\
$X^{2}=0.271, p>0.05$ & & & & & & \\
\hline
\end{tabular}

Seven PLWHA had been denied admission into public health facilities on the grounds of their HIV status before the time of the study. Out of these, $10.4 \%$ were women while $6.9 \%$ were men. Although the result shows that more women than men were denied admission, the difference was not statistically significant. These findings validate the findings of Reis et al., (2005) which revealed that $10 \%$ of the health workers refused PLWHA admission into their hospitals. They are also corroborated by the findings of the FGDs. FGD participants from the two LGAs copiously reported direct and indirect experiences of discrimination from health workers. For example a female FGD participant in Lagos Mainland LGA recalled her experience while on admission:

I had such an experience. Once the nurses see your file they know what's going on. I remem- ber they wanted to infuse a drip into me and they couldn't find my vein in my arm easily so they put it in my foot and because of it I could not move and I wanted to urinate and I kept calling the nurses they did not answer me and if I tried to move the leg the fluid would go into the tissue and blood would start flowing into the drip. When I called them they didn't answer me. One of them told me: "I don't have time for all this rubbish". Even when they wanted to give me drugs they would just enter and drop them without coming near me. It was my friend that came and went to meet them and told them that I was paying money so they had no choice but to take care of me.

Another female FGD participant gave an account of how she averted 
going to a public hospital in order to avoid discrimination and went to a private hospital to deliver her baby yet she suffered discrimination there. She reported that when she called for help the nurses ignored her. They were attending to other 'non PLWHA' patients. She said:

I decided to go to a Private hospital because I heard that at general hospital the nurses would be running away from you. Even in the private hospital the nurses collected N500 from me so that they could buy long gloves that would reach their shoulders (she demonstrated). They didn't take care at all; they collected the money while I was on the wheel chair to their theatre. The nurses don't take care at all. Some people that know about it would render help but the ignorant ones run away from you even amongst the nurses. Because of this nonsense I got a private room at the hospital. There was a nurse, I was in serious pain but this lady would not come to my room to help even when I called. She didn't answer me meanwhile she answered another patient so you can imagine the way people behaved and the way I felt.

These two instances show the magnitude and forms of social exclusion PLWHA go through in healthcare centres. They were isolated, neglected, ridiculed, and seldom received their drugs as at when due. This is a manifestation of unequal power, dominance and oppression validating the assertions of Foucault (1978) and Rich (1980). The findings also validate the findings of Iwuagwu et al., (2003).

All together, the findings revealed denial of treatment, mandatory HIV testing, segregation, isolation and ridicule. All these forms of discrimination except denial of admission into public hospitals showed that there were statistically significant differences between men and women's experiences. Women were more vulnerable in all except one. The findings are consistent with the findings of earlier studies. Women may be blamed for promiscuity because culturally, gender norms frown at female promiscuity while encouraging men to explore their sexual adventures. The findings also showed that some health workers were not knowledgeable about HIV infection. HIV infection is not transmitted by casual or direct contact and therefore does not warrant isolation except if the PLWHA also suffers from tuberculosis (TB). All these expose the high level of discrimination against PLWHA in the health sector.

Association between socioeconomic status of PLWHA and discrimination in the health sector

Having established in section 4.2 above that female PLWHA were more vulnerable to discrimination than males, the study went further to know the categories of males and females who suffered discrimination. Chi-square $\left(X^{2}\right)$ analysis was used to examine whether there were significant associations between socio-economic characteristics of the PLWHA and discrimination. Such characteristics include place of residence, age, marital status, education, employment status and income. The results for 
the men and women were presented comparison. together in Tables 4 below to allow for

Table 4: Distribution of socio-economic status of the PLWHA by sex and forms of discrimination in percentages

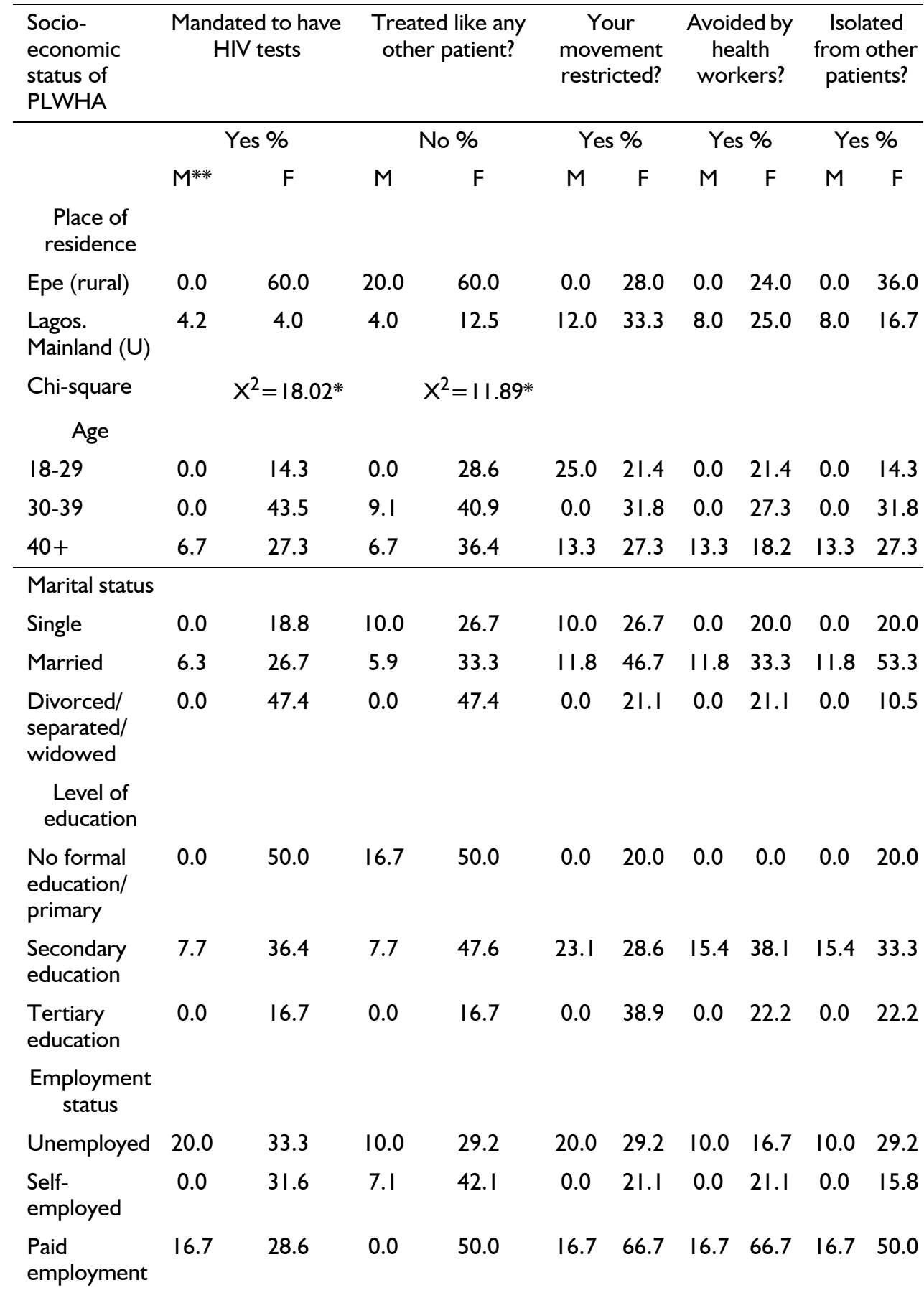


Income

\begin{tabular}{lllllllllll} 
No income & 0.0 & 33.3 & 10.0 & 29.2 & 20.0 & 29.2 & 10.0 & 16.7 & 10.0 & 10.0 \\
$\begin{array}{l}\text { Less than } \\
\text { NIO,000 }\end{array}$ & 0.0 & 50.0 & 14.3 & 66.7 & 0.0 & 33.3 & 0.0 & 41.7 & 0.0 & 0.0 \\
$\begin{array}{l}\text { NI0,00I- } \\
20,000\end{array}$ & 0.0 & 25.0 & 0.0 & 33.3 & 0.0 & 33.3 & 0.0 & 33.3 & 0.0 & 0.0 \\
\hline
\end{tabular}

${ }^{*} \mathrm{p}<0.001 ;{ }^{* *} \mathrm{M}=$ male; $\mathrm{F}=$ female.

General examination of Table 4 shows that the percentages of women who experienced any forms of discrimination were greater than those of the men. This is corroborating the conclusion in section 4.2 above. Analysing the association between place of residence and the various dimensions of discrimination indicates that rural female PLWHA were more likely to experience discrimination in the health sector than urban female PLWHA. The results from the analysis of the female PLWHA show a very high significant association between place of residence and mandatory HIV testing $\left(X^{2}=18.02 ; p<0.00 I\right)$. No male PLWHA from Epe LGA was mandated to do HIV tests, while threefifths of the females from Epe LGA were forced to do so. Similarly, place of residence of the female PLWHA had a significant association with unfair treatment $\left(X^{2}=11.89 ; p<0.00 I\right)$. In this case, only one fifth of the men in Epe LGA compared to three-fifths of the women in the same LGA were not appreciated like other patients. These results therefore showed that place of residence of the female PLWHA had a significant association with having been mandated to have HIV test and unfair treatment. To validate these findings, $36.0 \%, 28.0 \%$ and $24.0 \%$ of the women in Epe LGA reported segregation, restricted movements and social distance by health workers respec- tively while no man from Epe LGA reported such negative attitudes from the workers. Women living with HIV/ AIDS in rural Epe LGA were therefore more vulnerable to discrimination than men. They were also more vulnerable to discrimination than those in urban Lagos Mainland LGA. Results from the main study indicated a high level of discrimination in Epe LGA. This could explain the differences between rural and urban experiences. In fact a health worker living with HIV/AIDS in Epe LGA shared her experience with her fellow FGD participants:

In the General Hospital here in Epe, I was initially working in the ward when I noticed the behaviours of people towards me. They (my colleagues) and even patients were always reporting me for what l've not done. The reports got to the Medical Director, who now said I should be transferred to voluntary counselling and testing (VCT) Centre. The Medical director asked if it was okay by me and I consented. Initially my office was located in front. When I wanted to use the toilets, my colleagues or the cleaners wouldn't allow me and they would tell me 'they can't find the keys, or there is no water'. Initially I didn't know that it was because of my HIV 
status, that they were avoiding me. Most times I reported the attitudes to the matron. Later the Medical Director called all staff to enlighten them that the virus is not what can be contracted via physical contact or toilet. He warned them to stop avoiding the PLWHA. My office was relocated to another area within the facility. People who had previously stigmatized me now come asking to use the private toilet there. This is because what they expected to see in terms of my body and health was not what they saw; rather I am looking healthy and well fed.

This testimony indicates that the PLWHA was not only redeployed, her office was relocated. She was also excluded from the use of the staff toilets and avoided by her colleagues and patients. It also demonstrates the extent of discrimination and power relations within a micro setting as postulated by Foucault (1978). Secondly, it shows how the strong and non-infected people including health professionals control life chances against the women as argued by the radical feminists (Rich, 1980)

Analysis of age and discrimination indicates that female PLWHA of all age groups were more vulnerable than their male counterparts. Among the women, those living with HIV/AIDS aged 30-39 years were most vulnerable to discrimination (Table 4). A comparison between men and women shows that more female PLWHA aged $30-39$ years than male PLWHA of the same age ( $43.5 \%$ vs $0.0 \%$ ) complained of mandatory HIV testing. Women aged 30-39 years old $(40.9 \%)$ compared to men of the same age group (9.1\%) reported unfair treatment from the workers, $31.8 \%$ of the women aged $30-39$ years old were restricted and isolated from other patients while no male PLWHA experienced such discrimination. Women of this age group are likely to be married or were once in marital union (divorced, separated or widowed). Such groups of women are already vulnerable to stigmatization and discrimination in the society. Their status would exacerbate discrimination against them.

With respect to marital status, high percentages of divorced, separated and widowed female respondents experienced mandatory HIV testing (47.4\%) and unfair treatment by health workers (47.4\%) while none of the male PLWHA reported the same. Among the married respondents, greater proportions of women than men suffered segregation from other patients $(53.3 \%$ against $1 \mathrm{I} .8 \%$ ), movement restriction (46.7\% against II.8\%) and shunning by health workers $(33.3 \%$ compared to II.8\%). The study showed that married, divorced, separated and widowed women with HIV/AIDS were most susceptible to discrimination compared to others. Widows are generally more vulnerable than other women. They are more susceptible to being accused of infecting their spouses or being responsible for the death of their husbands in whatever way caused. On the other hand, widowhood for men does not bear such deleterious consequences. Men are not required to acquit themselves of guilt when their wives die. Divorced or separated people particularly women are also vulnerable. They 
are a marginalized group in the society. However, discrimination against widowed or separated or divorced PLWHA in this study may be attributed to misperception of HIV/AIDS. The study found that HIV infection was equated with sex and immorality, so these groups of female PLWHA might have been assumed to have contracted HIV/AIDS by promiscuous and immoral behaviours such as indulging in extramarital sex. For example, the belief by some non-infected respondents that only promiscuous people contract HIV/ AIDS reinforces negative beliefs supportive of discrimination.

On educational level analysis, the table shows that women with low education were mostly affected by mandatory HIV testing $(50.0 \%)$ and unjust treatment $(50.0 \%)$. These proportions were greater than those of their male counterparts $(0.0 \%$ for mandatory HIV testing and $16.7 \%$ for unjust treatment). No male PLWHA with tertiary education suffered any discrimination while $38.9 \%$ and $22.2 \%$ of female ones with the same educational level experienced movement restriction, avoidance and segregation respectively. Majority of the women with secondary education suffered discrimination more than the men e.g. unfair treatment $(47.6 \%$ vs $7.7 \%)$, segregation $(33.3 \%$ vs $15.4 \%)$ and isolation (38.1\% vs 15.4\%). This implies that both the less educated and highly educated female PLWHA suffer discrimination. It demonstrates that educational level of women living with HIV/AIDS does not insulate them from discrimination. This may be premised on the myths and stereotypes of HIV/AIDS that made people perceive PLWHA as untoucha- bles.

Association between employment status and discrimination shows that a great percentage of the women in paid reported negative attitudes of the health workers more than the men: restricted movement and social distance $(66.7 \%$ vs $16.7 \%$ each) and unequal treatment $(50.0 \%$ vs $0.0 \%)$. This shows that most female PLWHA who suffered different types of discrimination in health centres were in paid employment. Workers are more likely than others to be visiting health facilities frequently; hence they are more predisposed to discrimination than others.

None of the male PLWHA was coerced to do HIV tests whereas onehalf of the female ones who earned less than NI0,000 and one-third of those who received no income were forced to do so. While majority of the women who received less than $\mathrm{NI} 0,000$ as income suffered other various dimensions of discrimination no man with the same salary scale was subjected to inhumane treatment. Female PLWHA who earned no income and those who received less than $\mathrm{N} 10,000$ per month were very vulnerable to discrimination in the health sector. Low income PLWHA therefore experienced discrimination in the health care facilities more than the high income group. The study had earlier observed that more women than men were in low economic group. This is not surprising as women's low socio-economic status affects them. They are the ones who have low paid jobs. Secondly, wealthier people have the capacity to better manage both the flow of information relating to affected family members and the care of affected persons - at least until 
AIDS-related sickness begins to impose hard financial burdens upon individuals and the households.

In summary, this section revealed that socio-economic status of men did not have statistically significant influence on their vulnerability to discrimination whereas women's socio-economic status particularly place of residence had a statistically significant correlation with discrimination. In spite of lack of statistically significant correlation between discrimination and the other socioeconomic variables of the women, the study found that rural women in Epe LGA, those aged 30 - 39 years old; divorced, separated and widowed female PLWHA; those who earned less than NI0,000 and those in paid employment experienced different forms of discrimination in the health sector. Women, irrespective of their educational levels were predisposed to discrimination.

\section{Conclusion and recommendations}

The study found that the different forms of discrimination reported by the PLWHA were segregation, isolation, mandatory HIV tests, unjust treatment, ridicule, neglect and delayed administration of drugs to PLWHA patients on admission. Our hypothesis which stated that women were more vulnerable to discrimination in the health facilities than men was confirmed. The study found that the categories of women who suffered discrimination were the following: rural women; those aged 30 39 years, married, divorced, separated and widowed ones, those in paid employment and low income women. Based on these findings, the following are therefore recommended:

- The identification of the different forms of discrimination would inform policy decisions on issues related to discrimination within the healthcare facilities that should help in designing programmes that would elicit support for those caring for the PLWHA and for the health workers to better handle the PLWHA.

- This should be followed by a government's anti-discrimination policy supported by a law that will ensure the protection of PLWHA's rights. The right not to be subjected to discrimination is enshrined in the 1999 Constitution of the Federal Government of Nigeria and many international legal instruments. It is also contained in the 2003 HIV policy. Government should monitor the implementation of all the laws. It should also be able to challenge breaches to anti-discrimination legislation if and when they occur, with the help of supportive human rights lawyers and NGOs.

- Women were found to be more vulnerable to HIV/AIDS-related discrimination than men in the health sector. The United Nations General Assembly Special Session on HIV/AIDS in July 200I reiterated that discrimination against PLWHA, especially women, must be addressed to curb the spread of the HIV pandemic in the world. Addressing the gendered dimensions of discrimination against PLWHA requires concerted efforts to combat the endemic gender inequalities using the provisions of Convention on Elimination of 
all forms of Discrimination against Women (CEDAW) and the Constitution. Gender should be mainstreamed in all the policies and programmes concerning HIV/AIDS.

- Health care providers should be educated, retrained and re-orientated adequately so that they will not be reluctant to treat PLWHA. They should be adequately equipped and encouraged to observe the international standards in handling PLWHA and in protecting themselves without discriminating against the HIV/AIDS patients.

The Government should also ensure that health workers are protected through the provision of adequate materials to carry out their duties without fear of contagion.

\section{References}

Adebajo, S. B.; Bambgola, A. O. And Oyediran, M. A. (2003) "Attitudes of Health Care Providers to persons living with HIV/AIDS in Lagos State, Nigeria" in Okonofua, F.E. (Ed.) African Journal of Reproductive Health, 7 (I): 103 - II2.

Adeokun, L; Okonkwo, P and Ladipo, O. A. (2006) "The stigmatization of people living with HIV/AIDS" in Adeyi, O.; Kanki, P.; Odutolu, O. and Idoko, J. A. (Eds) AIDS in Nigeria: A nation on the threshold, USA: Harvard Centre for Population and Development Studies: 213-233

Adirieje, U. (2003) "Perspective on stigma and discrimination in the workplace" Report to Nigeria AIDS e-forum group, Afrihealth Information Projects, Tuesday, 24

\section{June 2003}

Aggleton, P. and Parker, R. (2002) A conceptual framework and basis for action: HIVIADIS stigma and discrimination, Geneva: UNAIDS

Akparanta - Emenogu, A. (2002) "How fares Nigeria's war against HIV/ AIDS?" Source: www.irinnews.org IRIN web Special on World AIDS Day.

Altman, D. (1972) Homosexual: Oppression and Liberation. Sydney: Angus and Robertson.

Arachu, C. and Farmer, P. (2005) "Understanding and Addressing AIDS-Related Stigma: From Anthropological Theory to Clinical Practice in Haiti", American Journal of Public Health. 2005 January; 95(I): 53-59.

Asia Pacific Network of People Living with HIV/AIDS (2004) "AIDS-related Discrimination and Human Rights", APN + Position Paper I

Brooks, R. A., Etzel, M. A. et al. (2005). "Preventing HIV among Latino and African American gay and bisexual men in a context of HIV-related stigma, discrimination, and homophobia: Perspectives of providers." AIDS Patient Care STDS, 19(II): 737-44.

Community Participation for Action in the Social Sectors (COMPASS), (2005) "Lagos State Profile" paper presented at the ARV Committee Meeting May 10, 2004

Durham, J. D. (1994) "The changing HIV/AIDS epidemic: emerging psychosocial challenges for nurses". Nurses Clinical of North America, 29: 9 - 18.

Durojaiye, E. (2003) Report of the seminar for lawyers and judges 
organised by Centre for the Right to Health (CRH), Lagos: CRH

Ekong, E. (2005) "Comparison of knowledge, attitude and practices on HIV/AIDS among the medical and infantry corps of the Nigerian Army" in Idigbe, E.D.; Harry T.O., Idoko T.A.; Ekong, E.k.; Audu, R.A.; Musa, A.Z.; Funsho-Adebayo, E.O.; and Onwuamah, C.K. (Eds). Nigerian contributions to regional and global meetings on HIV/AIDS/STIs 19862005, Lagos: NIMR; $2^{\text {nd }}$ ed. November 2005.

Family Health International (FHI), (200I) In-depth Assessment Report, Lagos: $\mathrm{FHI}$

Federal Government Printer (FGP), (2007) "Legal Notice on publication of the details of the breakdown of the national and state provisional totals 2006 census" Federal Republic of Nigeria Official Gazette, No. 24, Vol. 94, Lagos: $15^{\text {th }}$ May 2007: BI75 - 198

Federal Ministry of Health (Nigeria), (2003) National HIV/AIDS and Reproductive Health Survey (NARHS), 2003, Abuja, Nigeria: FMOH

Federal Ministry of Health (Nigeria), (2004) Technical Report on 2003 National HIV Sero-prevalence Sentinel Survey, Abuja, Nigeria: $\mathrm{FMOH}$

Federal Ministry of Health (Nigeria), (2006) Technical Report on 2005 National HIV Sero-prevalence Sentinel Survey, Abuja, Nigeria: FMOH

Foucault, M. (1978) The History of Sexuality: Volume I. New York: Vintage Books

Fredriksson, J. and Kanabus, A. (Eds) (2004) "HIV and AIDS stigma and discrimination: Attitudes towards HIV and AIDS", Addis Ababa:
African Development Forum

Gerbert, B.; Maguire, B. T.; Bleeker, T.; Coates, T. J. and McPhee, S. J. (I99I) "Primary care physicians and AIDS: Attitudinal and structural barriers to care". Journal of the American Medical Association, 266: 2837 - 2842

Gerth, H. and Mills, C. (Eds. and Trans.) (1958). From Max Weber: Essays in Sociology. New York: Oxford University Press.

Gilmore, N. and Somerville, M. A. (1994) "Stigmatization, scapegoating and discrimination in sexually transmitted diseases: overcoming 'them' and 'us' "Social Science and Medicine 39 (9): I339-I 358

Herek, G. M. and Capitanio, J. P. (1999) "AIDS stigma and sexual prejudice" American Behavioural Scientist, 1999; 42(7): I I 26-43.

Herek, G. and Glunt. E. K. (1988) "An epidemic of stigma: public reaction to AIDS." American Psychologist 43(II): 886-89I.

Iwuagwu, S.; Durojaiye, E.; Eziefule, B.; Oyebola, B.; Cnibututu, M.; Nwanguma, C. and Okekearu, B. (200I) Human rights and HIV/AIDS: Experiences of people living with HIV/ AIDS in Nigeria, Lagos: CRH

Iwuagwu, S.; Durojaiye, E.; Oyebola, B.; Oluduro, B. and Ayankobe, $\mathrm{O}$. (2003) HIV/AIDS and Human Rights in Nigeria: Background paper for HIV/ AIDS Policy Review in Nigeria, Lagos: CRH/USAID

Mann, J. (1987) "Statement at an informal briefing on AIDS to the 42nd session of the United Nations General Assembly", 20 October. New York.

National AIDS \& STD Control 
Programme, (NASCP) (2002) HIV/ AIDS in Nigeria: Overview of the epidemic, Federal Ministry of Health in Collaboration with the National Action Committee on AIDS (NACA) with Technical Assistance from Policy Project, Futures Group International funded by USAID

National Population Commission (1997) 1991 Census '9l national summary: 774 Local Government Areas, Abuja: NPC

National Population Commission, (NPC) (Nigeria) and ORC/Macro (2004) Nigeria Demographic and Health Survey 2003, (NDHS2003) Calverton, Maryland: NPC and ORC/Macro

Nigerian Institute of Medical Research (NIMR) (2000a) HIV/AIDS in Nigeria: Technical Report (Survey of Health and Laboratory Facilities) (19891999), National HIV/AIDS Database Project, Lagos: Federal Ministry of Science and Technology, $I^{\text {st }}$ edition

Nwanna, C. R. (2003) "Women and HIV/AIDS in Nigeria: Issues and challenges in the $21^{\text {st }}$ Century" UNILAG Sociological Review, Vol. 4, October 2003: 80 - 102

Reis, C.; Heisler, M.; Amowitz, L. L.; Moreland, R. S.; Mafeni, O.; Anyamele, C. and lacopino, V. (2005) "The Discriminatory Attitudes and Practices by Health Workers towards Patients with HIV", PLoS Medicine, 2005 August; 2(8): $26 \mathrm{I}$.
Rich A. heterosexual (1980) "Compulsory and lesbian experience" in Stimson, C. R. and Person (eds), Women, Sex and Sexuality, Chicago, University of Chicago Press: 62-91

Ritzer, G. (1996) Sociological theory, New York: The McGraw-Hill Companies Inc. $4^{\text {th }}$ edition

Sherafat-Kazemzadeh, R.; Shahraz, S.; Mohaghegh-Shalmani, H.; Ghaziani, T.; Faghahati, L.; Zali, M. and Mohraz, M. (2004) Iranian Persons Living with HIV/AIDS Unveil the Epidemic of Stigma (An overview of patients' attitudes towards the disease and community in first GIPA gathering in Tehran)

UNAIDS (1996) Protocol for the Identification of Discrimination against People Living with HIV, Geneva: UNAIDS, 1996, at 5

UNAIDS (2008) 2008 Report on the global AIDS epidemic, Geneva, UNAIDS

Weinberger, M.; Conover, C. J.; Samsa, G. P.; and Greenberg, S. M. (1992) "Physicians' attitudes and practices regarding treatment of HIV-infected patients" South Medical Journal; 85: 683-686

WHO (2008) WHO African Region: Nigeria, Geneva, WHO

Young, C. (2004) "What's New: QAP studies stigma in HIV/AIDS healthcare services in Rwanda" Healthcare and workplace improvement, QAP. 